\title{
Endometrial cancer with an EML4-ALK rearrangement
}

\author{
Jeffrey W. Craig, ${ }^{1}$ Bradley J. Quade, ${ }^{1}$ Michael G. Muto, ${ }^{2}$ and Laura E. MacConaill ${ }^{1,3}$ \\ ${ }^{1}$ Department of Pathology, Brigham and Women's Hospital, Harvard Medical School, Boston, Massachusetts \\ 02215, USA; ${ }^{2}$ Department of Obstetrics, Gynecology and Reproductive Biology, Brigham and Women's \\ Hospital, Harvard Medical School, Boston, Massachusetts 02215, USA; ${ }^{3}$ Center for Cancer Genome Discovery, \\ Dana-Farber Cancer Institute, Harvard Medical School, Boston, Massachusetts 02215, USA
}

\begin{abstract}
An 85-yr-old woman was diagnosed with endometrial adenocarcinoma, endometrioid type. Imaging studies showed a large tumor distending the endometrial canal without evidence of local invasion or extrauterine disease. A hysterectomy was performed, followed by microscopic examination of longitudinal tissue sections. Histopathological review showed only focal myometrial invasion, equivocal lymphovascular invasion, and negative bilateral sentinel lymph nodes (FIGO stage IA). A sample of the tumor was submitted for molecular testing (massively parallel sequencing on OncoPanel) and was found to harbor an inversion on Chromosome 2 resulting in an EML4-ALK gene fusion. Confirmatory immunohistochemistry showed ALK overexpression in just a portion of the tumor. Additional genomic characterization on a region of the tumor lacking ALK overexpression by immunohistochemistry was highly congruous with the genomic profile of the ALK-positive portion, showing similar patterns of copy-number variation and mutations in TP53 and KDM5C, with no evidence for an EML4-ALK gene fusion, confirming that EML4-ALK rearrangement had occurred as a subclonal process. EML4-ALK fusions are driver events in $2 \%-5 \%$ of non-small-cell lung cancers; crizotinib is an approved targeted therapy for these patients. EML4-ALK rearrangements have not previously been reported in endometrial cancer.
\end{abstract}

Corresponding author: Laura_Macconaill@dfci.harvard. edu

(c) 2018 Craig et al. This article is distributed under the terms of the Creative Commons Attribution-NonCommercial License, which permits reuse and redistribution, except for commercial purposes, provided that the original author and source are credited.

Ontology term: endometrial carcinoma

Published by Cold Spring Harbor Laboratory Press

doi: $10.1101 / \mathrm{mcs} . \mathrm{a} 003020$

\section{CASE PRESENTATION}

An 85-yr-old woman was diagnosed with endometrial adenocarcinoma, endometrioid type, grade 3 (of 3), via endometrial biopsy performed for post-menopausal bleeding. Imaging studies showed a large tumor distending the endometrial canal without evidence of local invasion or extrauterine disease. Subsequent total laparoscopic hysterectomy bilateral salpingo-oophorectomy with surgical staging revealed a $5.8 \mathrm{~cm}$, tan/white, exophytic mass involving the anterior aspect of the endometrial cavity. The polypoid nature of the tumor was most easily appreciated by microscopic examination of longitudinal tissue sections, where it appears folded over residual areas of benign endometrium (Fig. 1A). Further histopathological review showed only focal myometrial invasion, equivocal lymphovascular invasion, and negative bilateral sentinel lymph nodes (FIGO stage IA).

\section{TECHNICAL ANALYSIS AND METHODS}

A sample of the tumor ("sample 1"; estimated percentage of neoplastic cells was 70\%) submitted for genomic characterization using OncoPanel (version 3)-a hybrid-capture and 

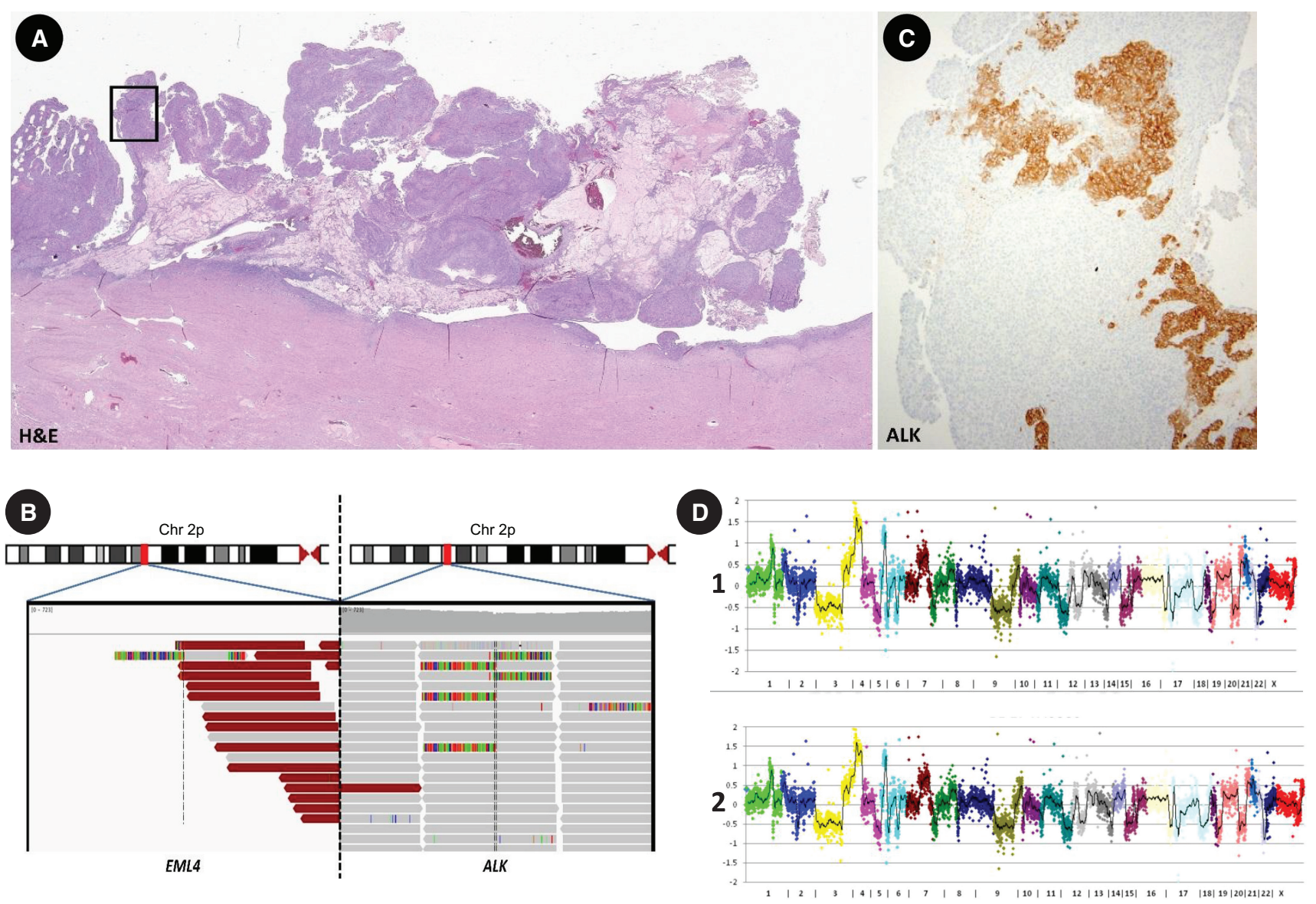

Figure 1. (A) H\&E slide of endometrial cancer specimen. (B) Genomic representation (IGV screenshot) of EML4-ALK fusion. (C) Immunohistochemical staining showing ALK overexpression in part of the specimen (shown boxed in A) only. (D) Plot of copy-number variation for specimen 1 (upper) and specimen 2 (lower) by color-coded chromosomes reveals a very similar pattern of copy-number alterations in the specimens. The vertical axis is the ratio of number of reads for this specimen and a panel of normals in log base 2 scale.

massively parallel sequencing assay. Testing was performed in a CLIA-certified laboratory as previously described (Sholl et al. 2016; Garcia et al. 2017). DNA was isolated with a kit (Qiagen) followed by ultrasonic fragmentation (Covaris), size selection, and quantification. Sequencing libraries were prepared using KAPA HTP library preparation kits (Roche) and hybridized to a biotinylated RNA bait set (Agilent SureSelect). The assay (OncoPanel) is designed to capture and sequence the full coding regions of 447 cancer genes; additional baits are tiled on intronic regions for 60 clinically relevant known rearrangement loci. Streptavidin-captured libraries were PCR-enriched, size selected, and sequenced on an Illumina HiSeq 2500 with $2 \times 100$ paired-end reads.

Sequence data were analyzed using a pipeline consisting of reconfigured publicly available tools and internally developed algorithms (RobustCNV, Anotate\&Phase, BreaKmer) as described previously (Sholl et al. 2016; Garcia et al. 2017). In brief, pooled sample reads were deconvoluted using Picard (version 1.13.0) and aligned using BWA to Human Genome Reference Consortium reference sequence b37 edition (duplicate reads were removed). Localized realignment around indel sites and recalibration of the quality scores was performed using the Genome Analysis Toolkit (McKenna et al. 2010; DePristo et al. 2011) 
(GATK, version 3.3.0). MuTect v. 10.27200 (Cibulskis et al. 2013) and Variant Effect Predictor (VEP) v79 were used to identify and annotate mutations; SomaticlndelDetector (v1.65) was used to identify small insertions and deletions. Normal FFPE samples were used to filter sequencing and batch-level artifacts. As a matched normal was not available, SNPs present at $>0.1 \%$ in Exome Variant Server, NHLBI GO Exome Sequencing Project (ESP), Seattle, WA (http://evs.gs.washington.edu/EVS; accessed May 30, 2013) were filtered unless also present in COSMIC at least twice. A custom R-based tool was used to call copy-number changes by calculating the fractional coverage of specified genomic intervals compared with the median fractional coverage obtained in a panel of 152 FFPE normal samples. Structural variant analysis was performed using BreaKmer (Abo et al. 2014) with visualization of sequences of interest in Integrative Genomics Viewer (IGV) (Robinson et al. 2011).

OncoPanel performance metrics were established for the assay using genomically wellcharacterized clinical samples as previously described (Garcia et al. 2017). In summary, sensitivity for SNVs was $97.8 \%$ (95\% Cl: 86.5\%-99.9\%), and for rearrangements was 74\% (95\% Cl: $53.4 \%-88.1 \%)$; specificity for SNVs was 100\% (95\% Cl: $99.9 \%-100 \%)$, and for rearrangements was $100 \%$ (95\% Cl: $69.9 \%-100 \%)$. Mean target coverage was $436 \times$ (unique, highquality, mapped reads) for sample 1 , and $310 \times$ for sample 2 . The mean percent target bases greater than $30 \times$ was $98 \%$ for both specimens.

\section{VARIANT INTERPRETATION}

Interestingly, sample 1 was found to harbor an inversion on Chromosome 2, involving a breakpoint within intron 19 of ALK and intron 21 of EML4. The resulting EML4-ALK fusion (Table 1 for genomic coordinates; Fig. 1B) contains the amino-terminal portion of EML4 and the entire intracellular portion of the ALK protein-including the juxtamembrane domain and the catalytic tyrosine kinase domain-the latter of which is the presumed functional driver. Immunohistochemistry (IHC) showed ALK overexpression in just a portion of the tumor, with the marbled interface between ALK-positive and ALK-negative areas showing otherwise homogenous morphologic features (Fig. 1A, black rectangle, and 1C). Subsequent molecular testing on a region of the tumor lacking ALK overexpression by IHC ("sample 2"; 70\% tumor) was highly congruous with the genomic profile of the ALK-positive portion (see Table 1): Both cases harbored mutations in TP53 (I251S) and KDM5C (K498N), among others, and similar patterns of copy-number variation (other than the inversion on Chromosome 2) across regions of the genome covered in our assay (Fig. 1D). The EML4-ALK gene fusion was notably absent, however, confirming that EML4-ALK rearrangement had occurred as a subclonal process (roughly estimated using mapped reads over the locus at $\sim 20 \%-30 \%$ allele burden in the tumor).

\begin{tabular}{|c|c|c|c|c|c|c|c|c|c|}
\hline \multirow[b]{2}{*}{ Gene } & \multirow[b]{2}{*}{$\mathrm{Chr}$} & \multirow[b]{2}{*}{ HGVS DNA ref } & \multirow{2}{*}{$\begin{array}{l}\text { HGVS } \\
\text { protein } \\
\text { ref }\end{array}$} & \multirow[b]{2}{*}{$\begin{array}{l}\text { Variant } \\
\text { type }\end{array}$} & \multirow[b]{2}{*}{$\begin{array}{l}\text { Predicted } \\
\text { effect }\end{array}$} & \multicolumn{2}{|c|}{ Specimen 1} & \multicolumn{2}{|c|}{ Specimen 2} \\
\hline & & & & & & $\begin{array}{c}\text { Allele } \\
\text { frequency }\end{array}$ & $\begin{array}{c}\text { Target } \\
\text { coverage }\end{array}$ & $\begin{array}{c}\text { Allele } \\
\text { frequency }\end{array}$ & $\begin{array}{c}\text { Target } \\
\text { coverage }\end{array}$ \\
\hline $\begin{array}{r}\text { EML4- } \\
A L K\end{array}$ & 2 & $\begin{array}{l}\mathrm{t}(2 ; 2)(\mathrm{p} 21 ; \mathrm{p} 23.2) \\
\quad \text { (Chr2:g.29447680- } \\
\quad 42554394\end{array}$ & & Fusion & $\begin{array}{l}\text { Sensitivity to } \\
\text { ALK inhibitor }\end{array}$ & $\mathrm{n} / \mathrm{a}$ & $50 x$ & Not detected & $50 x$ \\
\hline KDM5C & $x$ & c. $1494 G>T$ & p.K498N & Substitution & $\mathrm{n} / \mathrm{a}$ & $30 \%$ & $635 x$ & $35 \%$ & $406 x$ \\
\hline TP53 & 17 & c. $752 T>G$ & p.I251s & Substitution & $\mathrm{n} / \mathrm{a}$ & $37 \%$ & $201 x$ & $60 \%$ & $105 x$ \\
\hline
\end{tabular}




\section{SUMMARY}

This is the first report of an EML4-ALK rearrangement in endometrial cancer. EML4-ALK fusions are driver events in $2 \%-5 \%$ of non-small-cell lung cancers; moreover, crizotinib is an FDA-approved targeted therapy for lung cancer patients. Standard of care treatment for a FIGO Stage IA grade 3 endometrial cancer is vaginal brachytherapy, which was pursued in this case. It was noted that if the cancer recurs, ALK-directed adjuvant chemotherapy would be considered. Overall, the identification of this genomic result in an unexpected cancer type highlights the utility of using a comprehensive genomic approach to direct precision cancer therapy.

\section{ADDITIONAL INFORMATION}

\section{Data Deposition and Access}

Variants have been deposited as part of AACR Project GENIE (https://synapse.org/genie) and submitted to ClinVar (https://www.ncbi.nlm.nih.gov/clinvar/) under accession number SCV000778842.

\section{Ethics Statement}

The patient provided written, informed consent (protocol 11-104). This study was approved by the institutional review board of the Dana-Farber Cancer Institute and the Partners Human Research Committee.

\section{Acknowledgments}

The authors would like to acknowledge the Profile project at Dana-Farber Cancer Institute and Brigham and Women's Hospital, and the DFCl Oncology Data Retrieval System (OncDRS) for the aggregation, management, and delivery of the clinical and operational research data used in this project. The content is solely the responsibility of the authors.

Competing Interest Statement The authors have declared no competing interest.

Received March 23, 2018; accepted in revised form April 24, 2018

\section{Author Contributions}

J.W.C. acquired clinical data and images, performed the literature search, and wrote the report. M.G.M. was responsible for the clinical management of the patient. B.J.Q. provided the final histopathological diagnosis of the lesion. L.E.M. interpreted the molecular findings, wrote the report, and supervised the project. All authors contributed to critical revision and final approval of the report.

\section{REFERENCES}

Abo RP, Ducar M, Garcia EP, Thorner AR, Rojas-Rudilla V, Lin L, Sholl LM, Hahn WC, Meyerson M, Lindeman NI, et al. 2014. BreaKmer: detection of structural variation in targeted massively parallel sequencing data using kmers. Nucleic Acids Res 43: e19.

Cibulskis K, Lawrence MS, Carter SL, Sivachenko A, Jaffe D, Sougnez C, Gabriel S, Meyerson M, Lander ES, Getz G. 2013. Sensitive detection of somatic point mutations in impure and heterogeneous cancer samples. Nat Biotechnol 31: 213-219.

DePristo MA, Banks E, Poplin R, Garimella KV, Maguire JR, Hartl C, Philippakis AA, del Angel G, Rivas MA, Hanna $M$, et al. 2011. A framework for variation discovery and genotyping using next-generation DNA sequencing data. Nat Genet 43: 491-498.

Garcia EP, Minkovsky A, Jia Y, Ducar MD, Shivdasani P, Gong X, Ligon AH, Sholl LM, Kuo FC, MacConall LE, et al. 2017. Validation of OncoPanel: a targeted next-generation sequencing assay for the detection of somatic variants in cancer. Arch Pathol Lab Med 141: 751-758. 
McKenna A, Hanna M, Banks E, Sivachenko A, Cibulskis K, Kernytsky A, Garimella K, Altshuler D, Gabriel S, Daly M, et al. 2010. The Genome Analysis Toolkit: a MapReduce framework for analyzing next-generation DNA sequencing data. Genome Res 20: 1297-1303.

Robinson JT, Thorvaldsdóttir H, Winckler W, Guttman M, Lander ES, Getz G, Mesirov JP. 2011. Integrative genomics viewer. Nat Biotechnol 29: 24-26.

Sholl LM, Do K, Shivdasani P, Cerami E, Dubuc AM, Kuo FC, Garcia EP, Yonghui J, Davineni P, Abo RP. 2016. Institutional implementation of clinical tumor profiling on an unselected cancer population. JCl Insight 1: e87062. 


\section{COLD SPRING HARBOR Molecular Case Studies}

\section{Endometrial cancer with an EML4-ALK rearrangement}

Jeffrey W. Craig, Bradley J. Quade, Michael G. Muto, et al.

Cold Spring Harb Mol Case Stud 2018, 4: a003020

Access the most recent version at doi: $10.1101 /$ mcs.a003020

References This article cites 7 articles, 1 of which can be accessed free at:

http://molecularcasestudies.cshlp.org/content/4/4/a003020.full.html\#ref-list-1

License This article is distributed under the terms of the Creative Commons Attribution-NonCommercial License, which permits reuse and redistribution, except for commercial purposes, provided that the original author and source are credited.

Email Alerting Receive free email alerts when new articles cite this article - sign up in the box at the Service top right corner of the article or click here. 